\title{
Badania uciążliwości zapachowej powietrza zanieczyszczonego związkami siarki metodą odorymetryczną i chromatograficzną
}

\begin{abstract}
$\mathrm{W}$ artykule poruszono zagadnienia związane z badaniami jakości zapachowej powietrza atmosferycznego. Dokonano opisu układów analitycznych łączących techniki sensoryczne i instrumentalne w badaniach zapachu. Wytypowano grupę lotnych organicznych związków siarki stanowiących potencjalne zanieczyszczenia zapachowe powietrza. Przeprowadzono badania oznaczania intensywności zapachowej syntetycznych próbek powietrza atmosferycznego oraz zawartości zanieczyszczeń zapachowych w tych próbkach.
\end{abstract}

Słowa kluczowe: chromatografia gazowa, odory, związki siarki, odorymetria.

\section{Study of the nuisance of sulfur compounds contaminated air by odorimetry and chromatography methods}

\begin{abstract}
This article deals with issues related to the study of air quality. A description of the analytical systems combining sensory and instrumental techniques in odor studies was done. A group of volatile organic sulfur compounds was identified as potential air pollutants. Studies were conducted to determine the scent intensity of synthetic samples of ambient air, and the content of impurities fragrances in these samples.
\end{abstract}

Key words: gas chromatography, odors, sulphur compounds, odorimetry.

\section{Wprowadzenie}

Przedstawione w niniejszej publikacji wyniki badań stanowią kontynuację prac badawczych prowadzonych w Zakładzie Nawaniania Paliw Gazowych INiG - PIB [7-9] nad poszukiwaniem nowych obszarów zastosowań opracowanej w Instytucie Nafty i Gazu - Państwowym Instytucie Badawczym przystawki odorymetrycznej INiG - PIB, której głównym przeznaczeniem jest badanie jakości zapachowej gazów ziemnych. Urządzenie to posiada także potencjalne możliwości zastosowania do badań środowiskowych uciążliwości zapachowych powietrza atmosferycznego. Zgodnie z zamiarem autorów kolejny etap prac badawczych miał na celu opracowanie metody prowadzenia badań równoległych polegających na wykonywaniu pomiarów stężenia zanieczyszczeń siarkowych powietrza oraz pomiarów jakości zapachu dla tej samej próbki, w tym samym czasie i z użyciem jednego urządzenia pomiarowego. Urządzeniem tym jest ana- lizator chromatograficzny z detektorem elektrochemicznym (GCED), sprzężony z przystawką odorymetryczną INiG - PIB (zwaną dalej również Odorymetrem INiG - PIB i oznaczaną skrótem O INiG - PIB). Układ taki stanowi alternatywę dla większości stosowanych powszechnie metod badania jakości zapachu próbek gazowych, wymagających użycia dwóch przyrządów pomiarowych w celu wykonania analiz stężenia odoranta/-ów w badanym gazie oraz określenia jego zapachu. W takich układach obie analizy przeprowadzane są z pewnym przesunięciem czasowym. Zastosowanie wspomnianego powyżej, zaprojektowanego w INiG - PIB układu sprzężonego GC-O INiG - PIB pozwoli na wykonywanie obu pomiarów w sposób równoległy dla tej samej próbki. Będzie to miało wpływ nie tylko na zwiększenie wiarygodności wyników pomiarów, ale pozwoli również na skrócenie całego procesu analitycznego, począwszy od badanego gazu. 
Realizowane dotychczas w Zakładzie Nawaniania Paliw Gazowych INiG - PIB prace badawcze w zakresie obszarów zastosowań dla przystawki odorymetrycznej INiG - PIB dotyczyły zarówno badań syntetycznych i rzeczywistych próbek gazów ziemnych [7, 9], jak i syntetycznych próbek powietrza atmosferycznego, zanieczyszczonych wybranymi związkami siarki [8]. Prace badawcze opisane w tym artykule stanowią kontynuację wcześniejszych działań [8] mających na celu opracowanie metody prowadzenia badań równoległych stężenia zanieczyszczeń siarkowych w próbkach powietrza atmosferycznego metodą chromatograficzną, z równoczesnymi pomiarami jakości zapachu tych próbek. Zamiarem autorów było opracowanie ww. metody dla układu sprzężonego: analizator chromatograficzny z detektorem elektrochemicznym GCED - przystawka odorymetryczna INiG - PIB (O INiG - PIB).

\section{Przegląd metod badawczych zapachowej jakości powietrza}

W celu przedstawienia metod, jakimi przeprowadza się badania jakości zapachowej powietrza, konieczne jest ustalenie modelu opisu ilościowego. Jest to trudne, gdyż zapach jest wrażeniem zmysłowym, tym samym jest trudny do opisu ilościowego. W badaniach nad odorami oraz w próbach zmierzających do opisu i oceny zjawiska uciążliwości zapachowej uwzględniane są trzy podstawowe cechy zapachu:

- wyczuwalność - odnosi się do teoretycznego minimalnego stężenia odorantów stymulujących, które jest konieczne do wyczucia zapachu przez połowę populacji,

- intensywność - wrażenie zmysłowe zależne od wielkości bodźca, który to wrażenie wywołuje; oceniana w stopniach intensywności zapachu według umownie przyjętej skali zapachowej [np. 16],

- jakość hedoniczna - stopień odczuwalnej niechęci lub przyjemności, zależny od intensywności i rodzaju zapachu gazu [6].

Zasadniczo metody badania zapachu można podzielić na dwie poniższe grupy:

- analiza sensoryczna - opierająca się na ocenie wrażeń zapachowych odbieranych przez ludzki zmysł powonienia, których wyniki przedstawiane są zwykle w postaci intensywności zapachowej, stężenia progowego czy stężenia zapachowego $[3,11]$,

- analiza instrumentalna - oznaczanie ilościowe poszczególnych składników mieszaniny gazowej, odpowiedzialnych za jej zapach. Wśród tych metod wyróżnia się przede wszystkim chromatografię gazową sprzężoną z olfaktometrią.

Należy zaznaczyć, że niezwykle trudno jest badać zapachy przy użyciu samych metod instrumentalnych. Wynika to z faktu, że odczucie zapachu nie jest zależne tylko od samego zapachu, ale również od innych parametrów osobniczych, warunków zewnętrznych oraz oddziaływań między substancjami będącymi składnikami mieszaniny zapachowej. W literaturze opisano przykłady rozwiązań kombinowanych - instrumentalno-sensorycznych [1, 10, 11, 13, 14].

Analiza sensoryczna oznacza ocenę właściwości badanych próbek za pomocą jednego lub kilku zmysłów, stosowanych jako ,,aparat pomiarowy”. Dotyczy ona pomiarów wykonywa- nych w sposób gwarantujący powtarzalność i odtwarzalność wyników jedynie w przypadku rygorystycznego przestrzegania procedur, szczegółowo opisanych w odpowiednich normach [np. 15]. Normy te precyzują wymagania, które muszą spełniać zespoły osób oceniających odczynniki i sprzęt laboratoryjny oraz instalacje wentylacyjno-klimatyzacyjne. Określają metody sprawdzania sensorycznej wrażliwości uczestników pomiarów, sposoby prezentacji próbek i rejestracji wyników ocen, metody statystycznego opracowania wyników itp. Pomiarem zapachowej właściwości substancji zajmuje się dział analizy sensorycznej, określany terminem odorymetria $[4,5]$.

Podstawą teoretyczną odbierania wrażeń węchowych przez ludzki zmysł powonienia jest prawo psychofizyczne, definiowane równaniem Webera-Fechnera [3]. Zgodnie z nim intensywność odczuwania substancji zapachowej (odoranta) opisać można rosnącą funkcją jej stężenia za pomocą równania (1) w postaci logarytmicznej zależności pomiędzy intensywnością odczuwanego zapachu a stężeniem wywołującej go substancji:

$$
S=k_{W} \cdot \log I / I_{0}
$$

gdzie:

$S$ - wyczuwalna intensywność zapachu (wyznaczona teoretycznie),

I - fizyczna intensywność bodźca (stężenie zapachowe),

$I_{0}$ - stężenie progowe,

$k_{W}$-współczynnik Webera-Fechnera.

Parametry równania (1) wyznaczane są eksperymentalnie za pomocą urządzeń pomiarowych pozwalających na uzyskanie precyzyjnych rozcieńczeń badanej próbki odoranta, poddawanej ocenie sensorycznej, takich jak olfaktometr dynamiczny [6]. Eksperymentalne określenie wielu wartości wyczuwalnej intensywności $(S)$ zapachu odoranta na podstawie kolejnych zmian jego stężenia umożliwia wyznaczenie współczynnika Webera-Fechnera $\left(k_{W}\right)$ w sposób empiryczny. Wynik pomiaru jest obliczany na podstawie ocen zgromadzonych z udziałem zespołu o kontrolowanej sprawności węchu. Zgodnie z zaleceniami PN-EN 13725:2007 [15] w pomiarach 
stężenia zapachowego metodą rozcieńczeń dynamicznych powinny uczestniczyć osoby spełniające ściśle określone kryteria co do wrażliwości węchu, wyselekcjonowane zgodnie ze znormalizowanymi kryteriami indywidualnej wrażliwości na zapach [15] i poddawane stałym sprawdzeniom wrażliwości węchowej. Ich zadaniem jest sygnalizowanie, przy którym poziomie rozcieńczenia zaczynają wyczuwać zapach badanej próbki. W praktyce ten odpowiednio dobrany zespół ludzi ocenia zapach wylotowego strumienia mieszaniny gazów, uzyskanego np. we wspomnianym powyżej olfaktometrze. Jest to urządzenie stosowane do mieszania strumienia badanego gazu (zawierającego odorant lub odoranty) ze strumieniem gazu bezwonnego w zakresie od $<2^{7} \mathrm{do} \geq 2^{14}$, umożliwiające otrzymywanie precyzyjnych serii rozcieńczeń badanej próbki. Rozcieńczenie początkowe powinno być tak duże, żeby jej zapach nie był wyczuwalny. Zmniejszanie stopnia rozcieńczenia próbki (a tym samym zwiększanie stężenia) uzyskuje się przez zmiany przepływów gazów. Poglądowy schemat budowy olfaktometru dynamicznego przedstawiono na rysunku 1 .

W opisywanych tu metodach rozcieńczeń zakłada się, że krotność rozcieńczenia badanej próbki do uzyskania zaniku zapachu jest miarą pierwotnego natężenia zapachu. W czasie pomiarów określa się, w jakim stopniu należy rozcieńczyć próbkę badanego gazu czystym powietrzem, żeby jej zapach przestał być wyczuwalny. Wynikiem pomiaru olfaktometrycznego jest wartość stopnia rozcieńczenia próbki badanego gazu czystym powietrzem, po którym osiągany jest zespołowy próg wyczuwalności zapachu, czyli uśredniony dla zespołu ekspertów wykonujących badania próg wyczuwalności zapachu. Odpowiada to najmniejszej wartości stężenia odoranta/odorantów w powietrzu, które jest wyczuwalne przez zespół $\mathrm{w}$ warunkach pomiaru $\mathrm{z}$ prawdopodobieństwem 0,5 [15].
Zapachy w otoczeniu, będące przyczyną uciążliwości zapachowej, są bardzo trudne do zmierzenia. Jak już wcześniej wspomniano, najlepszym narzędziem do wykonywania takich ocen - „detektorem” (ocena poprzez wrażenie zapachowe) jest ludzki nos. Pomiar zapachu wymaga określonych obiektywnych i dających powtarzalne wyniki technik. Pomiary zapachu dotyczą głównie określania jego „mocy”. Jest ona wyrażana najczęściej w postaci intensywności zapachu bądź stężenia substancji zapachowej w mieszaninie z powietrzem (stężenie zapachowe wyrażane jest liczbą jednostek zapachowych - ilość odoranta/-ów, która po odparowaniu do $1 \mathrm{~m}^{3}$ obojętnego gazu w warunkach standardowych jest wyczuwalna przez członków zespołu oceniającego jako próg wyczuwalności zapachu - w metrze sześciennym powietrza $\left[\mathrm{ou} / \mathrm{m}^{3}\right]$ w warunkach pomiaru). Znormalizowana metoda olfaktometrii dynamicznej [15] jest ogólnie przyjętą przez kraje Unii Europejskiej metodą pomiaru stężenia zapachowego. Techniki olfaktometryczne są podstawowymi instrumentami ochrony przed odorami.

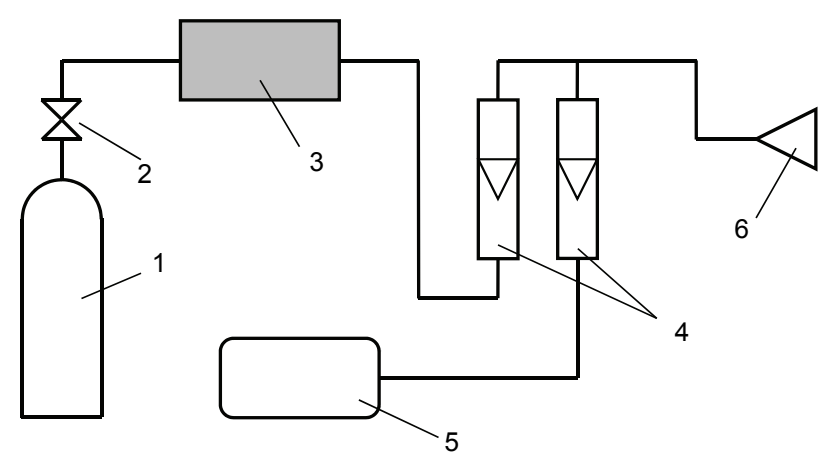

Rys. 1. Schemat ideowy oznaczania stężenia zapachu metodą rozcieńczeń dynamicznych przy użyciu olfaktometru:

1 - butla z bezwonnym powietrzem, 2 - zawór, 3 - filtr, 4 - rotametry, 5 - oznaczana próbka gazów, 6 - lejek węchowy

\section{Badania odorymetryczne syntetycznych próbek powietrza atmosferycznego}

Wśród związków odpowiedzialnych za uciążliwość zapachową powietrza (rozumianej jako stan dyskomfortu spowodowanego zapachem substancji występującej w powietrzu) wyróżnić można: związki siarki (głównie siarkowodór, tiole, sulfidy), związki azotu (głównie amoniak i aminy) oraz związki zawierające węgiel (jak aldehydy, ketony, kwasy karboksylowe, związki alifatyczne i aromatyczne). Do związków najbardziej nieprzyjemnych w odbiorze sensorycznym należą niewątpliwie związki siarki, odznaczające się dużą potencjalną uciążliwością zapachową. Stąd w badaniach rozpoznawczych możliwości wykorzystania metody określania jakości gazów ziemnych za pomocą przystawki odorymetrcznej w analizach uciążliwości zapachowej powietrza atmosferycznego skupiono się na pomiarach jakości zapachu powietrza spowodowa- nej lotnymi związkami siarki charakteryzującymi się bardzo nieprzyjemnym zapachem, a także niską granicą jego wyczuwalności. Związki te są emitowane miedzy innymi przez podmioty prowadzące działalność komunalną, takie jak składowiska odpadów lub oczyszczalnie ścieków, a więc zlokalizowane w pobliżu siedzib ludzkich, co stanowi uciążliwość dla mieszkańców takich rejonów. Wytyczne poboru próbek powietrza zanieczyszczonego odorami siarkowymi przedstawiono również we wcześniejszej publikacji autorów [8].

Na podstawie wcześniejszych badań wstępnych Zakładu Nawaniania Paliw Gazowych INiG - PIB [8], których efektem było sprzężenie przystawki odorymetrycznej O INiG - PIB $\mathrm{z}$ analizatorem chromatograficznym związków siarki wyposażonym w detektor elektrochemiczny GCED (w badaniach 
użyto analizatora typu MEDOR), opracowano metodykę prowadzenia równoległych analiz stężenia zapachowych związków siarki w gazie i analiz jakości zapachu paliw gazowych lub powietrza atmosferycznego. To innowacyjne podejście pozwoliło przede wszystkim skrócić czas prowadzenia badań zapachowych gazów i uprościć procedury pomiarowe. Schemat układu pomiarowego: przystawka odorymetryczna INiG - PIB - analizator chromatograficzny typu MEDOR (GCED - O INiG - PIB) przedstawiono na rysunku 2.

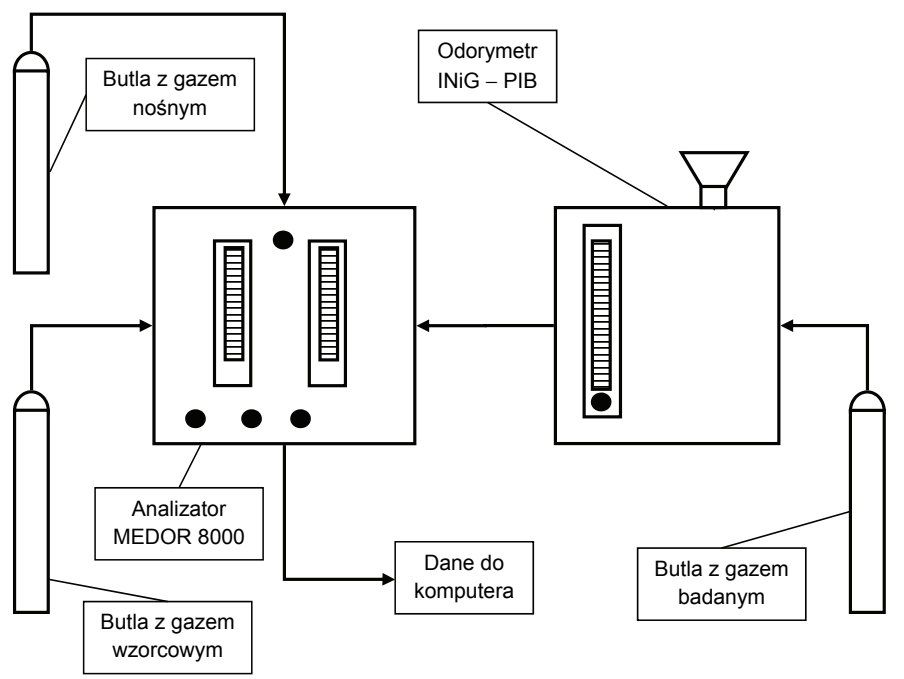

Rys. 2. Układ analityczny: analizator chromatograficzny przystawka odorymetryczna/Odorymetr INiG - PIB (GCED - O INiG - PIB) w konfiguracji do pomiarów równoległych stężenia zapachowych związków siarki $\mathrm{i}$ badania zapachu mieszanin gazowych

Na potrzeby realizacji opisywanych $\mathrm{w}$ artykule badań uciążliwości zapachowej powietrza atmosferycznego pochodzącej od związków siarki przygotowano próbki syntetyczne wybranych lotnych związków siarki stanowiących powszechne zanieczyszczenia zapachowe powietrza atmosferycznego, niebadanych w poprzednich etapach prac [8]. Przygotowano 4 próbki gazu [17] zawierające czyste merkaptany i sulfidy (merkaptan izo-propylowy, merkaptan tert-butylowy i siarczek dimetylu) oraz ich mieszaninę. Zawartość związków siarki w badanych próbkach dostosowano do ich średniej zawartości w powietrzu atmosferycznym zanieczyszczonym odorami.

Stężenia poszczególnych związków siarki oznaczono przy użyciu analizatora chromatograficznego typu MEDOR, zgodnie ze zoptymalizowaną w INiG - PIB metodą oznaczania związków siarki w gazach [12]. Matrycą przygotowanych próbek był azot. Skład oraz stężenie wybranych odorantów w próbkach zestawiono w tablicy 1.

Pomiary zapachu ww. próbek z równoległymi pomiarami stężenia poszczególnych zanieczyszczeń w tych próbkach prowadzono przy użyciu układu analitycznego skonstruowanego przez Zakład Nawaniania Paliw Gazowych INiG - PIB,
Tablica 1. Skład próbek syntetycznych powietrza atmosferycznego do badań odorymetrycznych (stężenia związków siarki oznaczono metodą chromatografii gazowej $\mathrm{z}$ detektorem elektrochemicznym)

\begin{tabular}{|l|c|}
\hline \multicolumn{1}{|c|}{ Nazwa związku } & $\begin{array}{c}\text { Stężenie } \\
\text { w próbce } \\
\text { powietrza } \\
\text { syntetycznego } \\
{\left[\mathrm{mg} / \mathrm{m}^{3}\right]}\end{array}$ \\
\hline Merkaptan izo-propylowy $\mathrm{C}_{3} \mathrm{H}_{7} \mathrm{SH}$ (i-PrSH) & $9,57 \pm 0,57$ \\
\hline Siarczek dimetylu $\left(\mathrm{CH}_{3}\right)_{2} \mathrm{~S}(\mathrm{DMS})$ & $10,50 \pm 0,52$ \\
\hline Merkaptan tert-butylowy $\mathrm{C}_{4} \mathrm{H}_{9} \mathrm{SH}(\mathrm{t}-\mathrm{BuSH})$ & $12,00 \pm 0,61$ \\
\hline Merkaptan izo-propylowy $\mathrm{C}_{3} \mathrm{H}_{7} \mathrm{SH}(\mathrm{i}-\mathrm{PrSH})$ & $1,37 \pm 0,07$ \\
Siarczek dimetylu $\left(\mathrm{CH}_{3}\right)_{2} \mathrm{~S}_{(\mathrm{DMS})}$ & $1,41 \pm 0,07$ \\
Merkaptan tert-butylowy $\mathrm{C}_{4} \mathrm{H}_{9} \mathrm{SH}(\mathrm{t}-\mathrm{BuSH})$ & $3,89 \pm 0,19$ \\
\hline
\end{tabular}

którego schemat ideowy przedstawiono na rysunku 2. Zasadę działania przystawki odorymetrycznej INiG - PIB oraz analizatora chromatograficznego typu MEDOR omówiono we wcześniejszych publikacjach [7, 8, 9], w których szerzej opisano również zasadę prowadzenia pomiarów równoległych. W badaniach zapachu uczestniczyła grupa ekspertów ww. zakładu INiG - PIB, dobrana zgodnie ze znormalizowanymi kryteriami [15] selekcji oceniających, biorąca udział w pracach badawczych nad innowacyjnymi metodami badań zapachu. Zespół spełniał wymagania normatywne [15] odnośnie kompetencji osób oceniających zapach, a jego liczebność została nieznacznie zmniejszona w stosunku do wymogu normy [15] z uwagi na rozpoznawczy charakter badań.

Pomiary intensywności zapachu próbek syntetycznych powietrza atmosferycznego $\mathrm{w}$ mieszaninie $\mathrm{z}$ czystym powietrzem prowadzono dla 3 poziomów stężeń badanego gazu: $0,5 \%, 1,0 \%$ oraz 1,5\%. Intensywność zapachu oceniano w stopniach według pięciostopniowej skali intensywności podanej w standardzie ST-IGG 0704:2014 [16], pozostając przy symbolice intensywności zapachu przyjętej w tym standardzie ( $I=S ; S$ - symbol intensywności zapachu według normy [15]). Uśrednione dla oceniających wyniki przeprowadzonych badań przedstawiono $\mathrm{w}$ tablicach $2-5$.

Otrzymane wyniki wyrażone w stopniach intensywności zapachu charakteryzują się akceptowalną odtwarzalnością wewnątrzlaboratoryjną [16]. Rozbieżności w wynikach stopni intensywności zapachu dla danego składu mieszaniny nie różnią się miedzy poszczególnymi ekspertami o więcej niż jeden stopień. Dla otrzymanych wyników zauważyć można nieznaczne różnice w intensywności zapachu poszczególnych próbek odnotowane dla tego samego stopnia ich rozcieńczenia (wyrażonego jako poziom zawartości próbki w czystym powietrzu), co jest efektem różnej wartości granicy wyczuwalności i charakterystyki zapachowej badanych mieszanin 
Tablica 2. Wyniki badań odorymetrycznych syntetycznej próbki powietrza nr 1 zawierającej merkaptan izo-propylowy

\begin{tabular}{|c|c|c|c|}
\hline \multirow{2}{*}{$\begin{array}{c}\text { Zawartość gazu badanego } \\
\text { (próbki powietrza synte- } \\
\text { tycznego) w mieszaninie } \\
\text { z czystym powietrzem } \\
{[\%]}\end{array}$} & \multicolumn{3}{|c|}{$\begin{array}{c}\text { Zmierzona intensywność } \\
\text { średnia zapachu }\end{array}$} \\
\cline { 2 - 4 } & ekspert 1 & ekspert 2 & ekspert 3 \\
\hline 0,5 & $I=0,5$ & $I=1$ & $I=1$ \\
\hline 1,0 & $I=2$ & $I=2$ & $I=2$ \\
\hline 1,5 & $I=4$ & $I=4$ & $I=4$ \\
\hline
\end{tabular}

Tablica 4. Wyniki badań odorymetrycznych syntetycznej próbki powietrza nr 3 zawierającej merkaptan tert-butylowy

\begin{tabular}{|c|c|c|c|}
\hline \multirow{2}{*}{$\begin{array}{c}\text { Zawartość gazu badanego } \\
\text { (próbki powietrza synte- } \\
\text { tycznego) w mieszaninie } \\
\text { z czystym powietrzem } \\
{[\%]}\end{array}$} & \multicolumn{3}{|c|}{$\begin{array}{c}\text { Zmierzona intensywność } \\
\text { średnia zapachu }\end{array}$} \\
\cline { 2 - 4 } & ekspert 1 & ekspert 2 & ekspert 3 \\
\hline 0,5 & $I=0,5$ & $I=0,5$ & $I=0,5$ \\
\hline 1,0 & $I=2$ & $I=2$ & $I=2$ \\
\hline 1,5 & $I=4$ & $I=3$ & $I=4$ \\
\hline
\end{tabular}

gazowych. Merkaptany izo-propylowy i tert-butylowy charakteryzują się niższą wartością granicy wyczuwalności w porównaniu z siarczkiem dimetylu.

Równolegle do analiz intensywności zapachu wygenerowanych próbek zawierających odorowe zanieczyszczenia siarkowe prowadzono pomiary zawartości tych zanieczyszczeń w tej samej próbce. Badania równoległe wykonano dla wszystkich syntetycznych próbek powietrza atmosferycznego podanych w tablicy 1 . Sposób prowadzenia badań był następujący: próbnik z gazem badanym podłączono do przystawki odorymetrycznej INiG - PIB, natomiast pętlę dozującą analizatora chromatograficznego sprzężono z wylotem układu próbkowania przystawki odorymetrycznej INiG - PIB. Skład mieszaniny gaz badany - czyste powietrze atmosferyczne, ocenianej przez zespół ekspertów, generowany był za pomocą przystawki odorymetrycznej INiG - PIB. Pozwoliło to na równoczesne wykonanie ocen intensywności zapachu mieszaniny oraz analizy zawartości w niej zanieczyszczeń siarkowych. Przykładowe uśrednione wyniki pomiarów uzyskane dla dwóch wybranych próbek zamieszczono w tablicach 6 i 7 .
Tablica 3. Wyniki badań odorymetrycznych syntetycznej próbki powietrza nr 2 zawierającej siarczek dimetylu

\begin{tabular}{|c|c|c|c|}
\hline \multirow{2}{*}{$\begin{array}{c}\text { Zawartość gazu badanego } \\
\text { (próbki powietrza synte- } \\
\text { tycznego) w mieszaninie } \\
\text { z czystym powietrzem } \\
{[\%]}\end{array}$} & \multicolumn{3}{|c|}{$\begin{array}{c}\text { Zmierzona intensywność } \\
\text { średnia zapachu }\end{array}$} \\
\cline { 2 - 4 } & ekspert 1 & ekspert 2 & ekspert 3 \\
\hline 0,5 & $I=0,5$ & $I=0,5$ & $I=0,5$ \\
\hline 1,0 & $I=2$ & $I=2$ & $I=2$ \\
\hline 1,5 & $I=3$ & $I=3$ & $I=3$ \\
\hline
\end{tabular}

Tablica 5. Wyniki badań odorymetrycznych syntetycznej próbki powietrza $\mathrm{nr} 4$ zawierającej mieszaninę merkaptanu izo-propylowego, siarczku dimetylu i merkaptanu tert-butylowego

\begin{tabular}{|c|c|c|c|}
\hline \multirow{2}{*}{$\begin{array}{c}\text { Zawartość gazu badanego } \\
\text { (próbki powietrza synte- } \\
\text { tycznego) w mieszaninie } \\
\text { z czystym powietrzem } \\
{[\%]}\end{array}$} & \multicolumn{3}{|c|}{$\begin{array}{c}\text { Zmierzona intensywność } \\
\text { średnia zapachu }\end{array}$} \\
\cline { 2 - 4 } & ekspert 1 & ekspert 2 & ekspert 3 \\
\hline 0,5 & $I=0,5$ & $I=0,5$ & $I=0,5$ \\
\hline 1,0 & $I=2$ & $I=2$ & $I=2$ \\
\hline 1,5 & $I=3$ & $I=3$ & $I=3$ \\
\hline
\end{tabular}

Tablica 6. Wyniki badań równoległych zapachu syntetycznej próbki powietrza atmosferycznego $\mathrm{nr} 2$ zawierającej siarczek dimetylu (DMS) oraz jego zawartości w próbce

\begin{tabular}{|c|c|c|}
\hline $\begin{array}{c}\text { Zawartość gazu badanego } \\
\text { (próbki powietrza syntetycznego) } \\
\text { w mieszaninie z czystym } \\
\text { powietrzem } \\
{[\%]}\end{array}$ & $\begin{array}{c}\text { Srednia intensyw- } \\
\text { ność zapachu dla } \\
\text { zespołu ekspertów }\end{array}$ & $\begin{array}{c}\text { Stężenie związku siarki } \\
\text { oznaczone przy użyciu } \\
\text { analizatora MEDOR } 8000 \\
{\left[\mathrm{mg} / \mathrm{m}^{3}\right]}\end{array}$ \\
\hline 0,5 & $I=0,5$ & DMS: $0,146 \pm 0,009$ \\
\hline 1,0 & $I=2$ & DMS: $0,243 \pm 0,015$ \\
\hline 1,5 & $I=3$ & DMS: $0,381 \pm 0,023$ \\
\hline
\end{tabular}

Tablica 7. Wyniki badań równoległych zapachu syntetycznej próbki powietrza atmosferycznego $\mathrm{nr} 4$ zawierającej merkaptan izo-propylowy (i-PrSH), siarczek dimetylu (DMS) i merkaptan tert-butylowy (t-BuSH) oraz ich zawartości w próbce

\begin{tabular}{|c|c|c|}
\hline $\begin{array}{c}\text { Zawartość gazu badanego } \\
\text { (próbki powietrza syntetycznego) } \\
\text { w mieszaninie z czystym } \\
\text { powietrzem } \\
{[\%]}\end{array}$ & $\begin{array}{c}\text { Średnia intensyw- } \\
\text { ność zapachu dla } \\
\text { zespołu ekspertów }\end{array}$ & $\begin{array}{c}\text { Stężenie związku siarki } \\
\text { oznaczone przy użyciu } \\
\text { analizatora MEDOR } 8000 \\
{\left[\mathrm{mg} / \mathrm{m}^{3}\right]}\end{array}$ \\
\hline 0,5 & $I=0,5$ & $\begin{array}{c}\text { i-PrSH: }<0,023 \\
\text { DMS: }<0,012 \\
\text { t-BuSH: }<0,089\end{array}$ \\
\hline 1,0 & $I=2$ & $\begin{array}{c}\text { i-PrSH: } 0,025 \pm 0,002 \\
\text { DMS: } 0,015 \pm 0,001 \\
\text { t-BuSH: } 0,092 \pm 0,005\end{array}$ \\
\hline 1,5 & & $\begin{array}{c}\text { i-PrSH: } 0,032 \pm 0,002 \\
\text { DMS: } 0,210 \pm 0,013 \\
\text { t-BuSH: } 0,170 \pm 0,011\end{array}$ \\
\hline
\end{tabular}




\section{Podsumowanie}

Wyniki zaprezentowane w niniejszym artykule oraz wcześniejszych publikacjach autorów [7-9] stanowią punkt wyjścia do rozszerzenia zakresu prac badawczych Zakładu Nawaniania Paliw Gazowych INiG - PIB o nowoczesne metody pomiarów odorymetrycznych, zarówno w obszarze badań zapachowej jakości paliw gazowych, jak i powietrza atmosferycznego.

Temat ten stanowi kontynuację prac badawczych mających na celu budowę urządzenia do pomiarów zapachowych gazów sprzężonego z chromatografem gazowym oraz jego wdrożenie do stosowania w praktyce laboratoryjnej. Układ GC-O (chromatograf gazowy - przystawka odorymetryczna) stanowi jedną z nowoczesnych technik pomiarów zapa- chu, określaną mianem chromatograficzno-gazowej olfaktometrii rozcieńczeniowej.

Przeprowadzone badania potwierdziły możliwość wykonywania równoległych analiz zawartości lotnych organicznych związków siarki (zarówno środków nawaniających paliwa gazowe, jak i związków odpowiadających za uciążliwość zapachową powietrza atmosferycznego) oraz badań intensywności zapachu w układzie sprzężonym, nie tylko dla próbek gazów ziemnych, ale również próbek powietrza atmosferycznego. Jednym z najważniejszych efektów tych wieloetapowych badań jest rozszerzenie możliwości aplikacyjnej przystawki odorymetrycznej INiG - PIB na obszar kontroli jakości zapachu powietrza atmosferycznego.

Prosimy cytować jako: Nafta-Gaz 2017, nr 12, s. 958-963, DOI: 10.18668/NG.2017.12.07

Artykuł nadesłano do Redakcji 9.12.2016 r. Zatwierdzono do druku 6.09.2017 r.

Artykuł powstał na podstawie pracy statutowej pt.: Badania uciążliwości zapachowej powietrza spowodowanej obecnościa wybranych zwiąków siarki w układzie sprzężonym GCED-przystawka odorymetryczna INiG - PIB - praca INiG - PIB na zlecenie MNiSW; nr zlecenia: 0065/WN/16/01, nr archiwalny: DK-4100-84/16.

\section{Literatura}

[1] Benzo M., Gilardoni G. et al.: Determination of the threshold odor concentration of main odorants in essential oils using gas chromatography-olfactometry incremental dilution technique. Journal of Chromatography A 2007, vol. 1150, s. 131-135.

[2] Gaja K., Kuropka J.: Powietrze atmosferyczne: Jakość - zagrożenia ochrona. Oficyna Wydawnicza Politechniki Wrocławskiej, 2016.

[3] Kolasińska P., Dymerski T., Namieśnik J.: Metody analizy sensorycznej jako narzędzie do oceny uciążliwości zapachowej powietrza atmosferycznego. Cz. I-podstawy teoretyczne. Analityka 2015, $\mathrm{nr} 4$, s. $8-11$.

[4] Kolasińska P., Dymerski T., Namieśnik J.: Metody analizy sensorycznej jako narzędzie do oceny uciążliwości zapachowej powietrza atmosferycznego. Cz. II - charakterystyka metod analizy sensorycznej. Analityka 2016, nr 1, s. 4-10.

[5] Kolasińska P., Dymerski T., Namieśnik J.: Metody analizy sensorycznej jako narzędzie do oceny uciążliwości zapachowej powietrza atmosferycznego. Cz. III-zastosowanie. Analityka 2016, nr 1 , s. $48-53$.

[6] Kośmider J., Mazur-Chrzanowska B., Wyszyński B.: Odory. Wydawnictwo Naukowe PWN, Warszawa 2002.

[7] Lisman Sz., Huszał A.: Badania jakości gazów ziemnych przy użyciu przystawki odorymetrycznej INiG - PIB sprzężonej z analizatorem chromatograficznym wyposażonym $w$ detektor elektrochemiczny. Nafta-Gaz 2015, nr 12, s. 1024-1029, DOI: 10.18668/NG2015.12.11.

[8] Lisman Sz., Huszał A.: Badanie zależności zapachowej jakości powietrza od zawartości zanieczyszczeń siarkowych z użyciem przystawki odorymetrycznej INiG - PIB. Nafta-Gaz 2016, nr 7, s. 539-545, DOI: $10.18668 / \mathrm{NG} .2016 .07 .07$

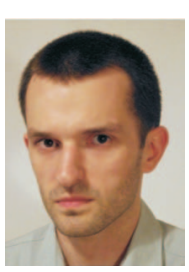

Mgr inż. Szymon LISMAN

Specjalista inżynieryjno-techniczny w Zakładzie

Nawaniania Paliw Gazowych.

Instytut Nafty i Gazu - Państwowy Instytut Badawczy

ul. Lubicz $25 \mathrm{~A}$

31-503 Kraków

E-mail:szymon.lisman@inig.pl
[9] Lisman Sz., Huszał A.: Dostosowanie prototypu przystawki odorymetrycznej sprzężonej z chromatografem gazowym do oznaczeń zapachowej jakości gazów. Nafta-Gaz 2015, nr 3, s. 190-194.

[10] Littarru P.: Environmental odours assessment from waste treatment plants: Dynamic olfactometry in combination with sensorial analysers ,electronic noses”. Waste Management 2007, vol. 27, s. 302-309.

[11] Sówka I.: Metody identyfikacji odorotwórczych gazów emitowanych z obiektów przemystowych. Oficyna Wydawnicza Politechniki Wrocławskiej, Wrocław 2011

[12] Szlęk M., Holewa J.: Optymalizacja metody oznaczania zawartości zwiazków siarki wystepujacych w paliwach gazowych. Nafta-Gaz 2015, nr 5, s. 308-313.

[13] Xiaofen D., Mei S. et al.: Identification of sulphur volatiles and $G C$-olfactometry aroma profiling in two fresh tomato cultivars. Food Chemistry 2015, vol. 171, s. 306-316.

[14] Zhang S., Cai L., Koziel J. et al.: Field air sampling and simultaneous chemical and sensory analysis of livestock odorants with sorbent tubes and GC-MS/olfactometry. Sensors and Actuators B: Chemical 2010, vol. 146, s. 427-432.

\section{Akty prawne i normatywne:}

[15] PN-EN 13725: 2007 Jakość powietrza. Oznaczanie stężenia zapachowego metoda olfaktometrii dynamicznej.

[16] ST-IGG-0704: 2014 Nawanianie paliw gazowych. Kontrola nawaniania paliw gazowych metodami odorymetrycznymi.

[17] VDI 3880:2011-10 Olfactometry - Static sampling.

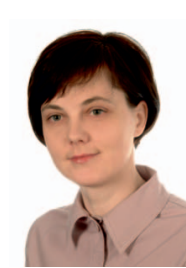

Dr Anna HUSZAł

Adiunkt; kierownik Zakładu Nawaniania Paliw Gazowych.

Instytut Nafty i Gazu - Państwowy Instytut Badawczy ul. Lubicz 25 A

31-503 Kraków

E-mail: anna.huszal@inig.pl 